University of Windsor

Scholarship at UWindsor

2016

\title{
Determination of the gut retention of plastic microbeads and microfibers in goldfish 1 (Carassius auratus)
}

\author{
Stefan Grigorakis \\ University of Windsor \\ Sherri A. Mason \\ State University of New York at Fredonia \\ Ken G. Drouillard \\ University of Windsor
}

Follow this and additional works at: https://scholar.uwindsor.ca/glierpub

Part of the Biochemistry, Biophysics, and Structural Biology Commons, Biodiversity Commons, Biology Commons, and the Marine Biology Commons

\section{Recommended Citation}

Grigorakis, Stefan; Mason, Sherri A.; and Drouillard, Ken G.. (2016). Determination of the gut retention of plastic microbeads and microfibers in goldfish 1 (Carassius auratus). Chemosphere, 169, 233-238.

https://scholar.uwindsor.ca/glierpub/125

This Article is brought to you for free and open access by the Great Lakes Institute for Environmental Research at Scholarship at UWindsor. It has been accepted for inclusion in Great Lakes Institute for Environmental Research Publications by an authorized administrator of Scholarship at UWindsor. For more information, please contact scholarship@uwindsor.ca. 
1 Title: Determination of the gut retention of plastic microbeads and microfibers in goldfish

2 (Carassius auratus)

3

\section{Author Names and Affiliations}

5 Stefan Grigorakis ${ }^{1}$, Sherri A. Mason ${ }^{2}$, Ken G. Drouillard ${ }^{1}$

$6{ }^{1}$ Great Lakes Institute for Environmental Research, University of Windsor, Windsor, ON,

7 Canada, N9B 3P4

$8 \quad{ }^{2}$ State University of New York at Fredonia, Department of Chemistry and Biochemistry, 280

9 Central Avenue, Science Complex 340, Fredonia, NY 14063, USA

\section{Corresponding author}

12 Ken G. Drouillard

13 Great Lakes Institute for Environmental Research,

14 University of Windsor

15401 Sunset Ave,

16 Windsor, ON, N9B 3P4

17 Tel: +1 (519)-253-3000 ext $4744 \quad$ Mobile: +1 (519)-903-5422

18 Fax: +1 (519)-971-3616

19 Email: kgd@uwindsor.ca

20

21

22 


\section{Abstract}

24 Microplastics are ubiquitous pollutants in aquatic habitats and commonly found in the gut

25 contents of fish yet relatively little is known about the retention of these particles by fish. In this

26 study, goldfish were fed a commercial fish food pellet amended with 50 particles of one of two

27 microplastics types, microbeads and microfibers. Microbeads were obtained from a commercial

28 facial cleanser while microfibers were obtained from washed synthetic textile. Following

29 consumption of the amended pellet, fish were allowed to feed to satiation on non-amended food

30 followed by fasting for periods ranging from $1.5 \mathrm{~h}$ to 6 days. Fish sacrificed at different time

31 points were dissected to remove gut contents and the digesta contents retention and microplastic

32 retention was determined. Although a small number of microplastic particles were retained in

33 fish GI-tracts after 6 days (0-3 particles/50), the retention of microplastics was generally similar

34 to the retention of bulk digesta contents. According to a breakpoint regression model fitted to

35 digesta contents and microplastic particles, the $50 \%$ and $90 \%$ evacuation times were $10 \mathrm{~h}$ and

$36 \quad 33.4 \mathrm{~h}$, respectively. The results of this study indicate that neither microbeads nor microfibers are

37 likely to accumulate within the gut contents of fish over successive meals.

Keywords: microplastics, bioaccumulation, gut retention, microbeads, microfibers

\subsection{Introduction}

Microplastics are a diverse array of synthetic polymer particles that vary in chemical

42 composition, size (from low micrometre scale to an upper size range variously defined between 1

$43 \mathrm{~nm}$ and $5 \mathrm{~mm}$ ), density and shape (Andrady, 2011). They have been observed in most freshwater

44 and marine environments (Eriksen et al., 2014; Corcoran, 2015; Eerkes-Medrano et al., 2015) to

45 such an extent that they were included as sedimentary geochemical markers of the Anthropocene 
46 (Waters et al., 2016). Microplastics are often distinguished between those that are synthesized at

47 the defined sizes for an intended application (primary microplastics) relative to particles derived

48 from the breakdown of macroplastics (secondary microplastics). Microbeads are defined as

49 primary microplastics that range in size between $0.1 \mu \mathrm{m}$ to $<5 \mathrm{~mm}$ (Environment Canada, 2015)

50 and are used in a wide variety of industrial and consumer applications including personal care

51 products (PCPs). Legislation banning the production of microbeads in PCPs comes into effect in

522017 as passed by the U.S. federal government and similar legislation is under review in Canada.

53 While much of the legislative focus has been on microbeads used in PCPs, other common

54 sources of microplastics to municipal wastewaters include abraded particles from synthetic

55 textiles such as nylon and acrylics, henceforth referred to as microfibers, used in clothing

56 (Browne, 2011).

57 Concerns have been raised about the ecotoxicology of microplastics in the environment,

58 including their potential to bioaccumulate in organisms and subsequent transfer through food

59 webs (Sánchez et al., 2014). Zooplankton are capable of ingesting microplastics, potentially

60 mistaking them for food, and can further transfer these to tertiary consumers (Frias et al., 2014;

61 Browne et al., 2013; Setala et al., 2014; Rehse et al., 2016). Mussels have been shown to

62 accumulate microplastics and transfer them to higher trophic levels (Browne et al., 2013; von

63 Moos et al., 2012; Collignon et al., 2012). In a study examining 504 fish from the English

64 Channel that included benthic and pelagic species, $36.5 \%$ of specimens had microplastics in their

65 gastrointestinal (GI-) tracts (Lusher et al., 2013). Microplastics in the gut contents of field

66 collected fish have subsequently been widely reported in coastal and freshwaters (Sanchez et al.,

67 2014; Neves et al., 2015; Avio et al, 2015; Phillips and Bonner, 2015; Biginagwa et al., 2016; 
Bellas et al., 2016). Considering microplastics are being found in fish, there are relatively few

69 studies focussing on the potential of microplastics to bioaccumulate.

Exposure to microplastics in water and food can interfere with normal digestive processes

71 due to intestinal blockage, causing reductions in animal feeding rates and energy assimilation

72 (Besseling et al., 2012), lead to histopathological alteration to intestinal and hepatic tissues of

73 fish (Pedà et al. 2016; Lu et al., 2016) and lower hatching success of fish eggs (Lönnstedt and

74 Eklöv, 2016). Translocation of microplastics from gut to the circulatory system has been

75 demonstrated in mussels (Browne et al., 2008; von Moos et al., 2012; Avio et al. 2015a)

76 implying that retention of microplastics beyond entrainment in the GI-tract may be possible in

77 some animals. Avio et al., (2015b) and Lu et al., (2016) confirmed microplastics accumulation in

78 hepatic tissues of fish exposed to microplastics at elevated concentrations in water.

Although microplastics are commonly detected in the intestinal tracts of fish, there is

80 limited information characterizing the retention of microplastics by fish. Particle size and shape

81 are likely to influence factors such as GI-retention but limited information is available comparing

82 microplastic types. Neves et al. (2015) observed a higher frequency of fibers in commercial fish

83 gut contents compared to plastic fragments. The above study further reported differences in

84 plastic types in benthic fish, which tended to accumulate a greater proportion of fibers, compared

85 to pelagic fish which contained more fragments. It is not known whether these differences are

86 related to emission patterns and fate of different particle types or whether particle shape might

87 influence the gut retention characteristics of these microplastic types. In this study, the GI-tract

88

retention of two microplastic types, microbeads and microfibers, was determined in goldfish with

89

the objective to determine if i) retention of microplastics by fish exceeds that of food digesta, i.e. 
90 exhibits net accumulation in the GI-tract of fish, and ii) to determine if microfibers are retained

91 to a greater or lesser degree than PCP derived microbeads.

$93 \quad 2.0$ Methods

94

\subsection{Microplastic source}

Microfibers were extracted from clothing $(35 \mathrm{~cm}$ x $12 \mathrm{~cm}$ cut out of a commercial

97 polyester fleece scarf) by mechanical agitation in hot water. Following agitation, the water was

98 sieved through stacked $500 \mu \mathrm{m}, 250 \mu \mathrm{m}$ and $63 \mu \mathrm{m}$ sieves. Fibers retained on the $63 \mu \mathrm{m}$ sieve

99 were removed by tweezer under magnification and size graded to between $50-500 \mu \mathrm{m}$ fiber

100 lengths under a dissecting microscope. Microplastic beads were extracted from a commercial

101 cosmetic product (facial cleanser labelled with polyethylene). The contents of the product was

102 poured onto a 63 sieve and the soluble matrix associated with the product washed with water

103 until only microplastics remained. Microbeads were removed from the sieve under

104 magnification. Figure 1 provides images of isolated microbeads and microfibers under 5x

105 magnification.

$106 \quad 2.2$ Experimental

107 Goldfish were selected as a model fish species because they have been routinely used in 108 many bioaccumulation/toxicokinetic studies owing to the ease of husbandry, tolerance to 109 handling and willingness to accept artificial diets. In their wild state, goldfish are benthic feeders 110 and thus might be expected to accumulate microplastics similar to those reported for other

111 benthic feeders. Fish were exposed to microplastics via food. Commercial fish pellets $(0.18-$

$1120.21 \mathrm{~g}, \sim 3 \mathrm{~mm}$ size) were placed in warm water to soften them. Treatment pellets were amended 
113 with 50 microbeads or 50 microfibers per pellet by manual insertion of macroplastic particles

114 into each pellet under microscope. Pellets were air dried after manipulation. Control pellets were

115 wetted and dried in an identical manner but not amended with microplastics. The food was

116 prepared in this manner to ensure that every experimental fish consumed exactly 50 microplastic

117 particles to increase precision of gut retention characterization.

Fifty three sexually mature goldfish were fasted for $48 \mathrm{~h}$ prior to exposing them to

119 prepared food in order to ensure complete evacuation of gut contents from previous meals and to

120 increase the likelihood that they would accept the microplastic amended pellet provided to them.

121 After fasting, fish were removed from their communal tank and placed in individual fish bowls.

122 Twenty four fish were allocated to the microbead and microfiber treatments, respectively. Five

123 fish were allocated as controls and fed non-amended pellets. Each fish was presented with a

124 single treatment pellet and observed until it was verified that the fish consumed the pellet. After

125 the fish consumed the treatment pellet, non-amended fish pellets were added to the bowl and the

126 fish was allowed to consume to satiation for up to 60 minutes. Any remaining fish food in the

127 bowl was subsequently removed. Fish were fasted for the remainder of the experimental period.

128 Control fish were sacrificed after $1.5 \mathrm{~h}$ from feeding the control pellets. Triplicate animals from

129 each treatment were sacrificed after $1.5,4,8,16,32,48,96$, and $144 \mathrm{~h}$. The mean \pm SE of water

130 temperatures was $14.2 \pm 0.21{ }^{\circ} \mathrm{C}$ and exhibited no changes over the fasting duration. The mean \pm

131 SE body weights of fish from the microbead and microfiber treatments were $24.80 \pm 2.77 \mathrm{~g}$ and

$13227.07 \pm 3.40 \mathrm{~g}$ and were not significantly different from one another $(\mathrm{p}>0.4$; ANOVA). On

133 sacrifice, fish were euthanized by immersion in a solution of MS-222 (100 mg/L) and stored

134 frozen until subsequent analysis. This research was performed under ethics approval from the

135 University of Windsor's Animal Care Committee. 


\subsection{Microplastic analysis}

On analysis, the gut tract of each fish was dissected and removed. The gut contents were pushed thought the intestine using tweezers and a probe onto a pre-weighed aluminum weight boat and the gut tract tissues were retained for further analysis. The weigh boat was dried at

$141 \quad 110^{\circ} \mathrm{C}$ for $1 \mathrm{~h}$ and reweighed to determine dry food digesta weight. Subsequently, the dried 142 digesta and gut tissues were re-combined and placed into a $10 \% \mathrm{KOH}$ solution on a hot plate set 143 at its lowest setting for 1 hour. The solution was taken off of the hot plate and after 2 additional 144 hours, $5 \mathrm{~mL}$ of $30 \% \mathrm{H}_{2} \mathrm{O}_{2}$ was added to the solution. The solution was poured through a vacuum 145 filtered Buchner funnel using Whatman ${ }^{\mathrm{TM}}(55 \mathrm{~mm})$ filter papers ( $1 \mu \mathrm{m}$ glass fiber filters). Fish 146 carcass samples were also digested in a similar manner. Filter papers from each digestion were 147 analyzed under a stereomicroscope to quantify the number of microplastics remaining in the GI148 tract/contents, fish carcass or digested food pellets. Quality control of the method was 149 established by measuring and verifying microbeads and microfibers in 5 amended pellets. The 150 mean \pm standard deviation of recoveries of microplastic particles for the digested pellets was $15198.8 \pm 1.8 \%$.

\subsection{Data analysis}

Digesta contents weights were standardized to the mean body weight according to:

$$
X_{D G(s s)}=X_{D G(s)} \cdot \frac{B W_{(m e a n)}}{B W_{(s)}}
$$

where $\mathrm{X}_{\mathrm{DG}(\mathrm{ss})}$ is the size standardized digesta weight $(\mathrm{g}), \mathrm{X}_{\mathrm{DG}(\mathrm{s})}$ is the digesta weight measured in

157 an individual fish, $\mathrm{BW}_{(\text {mean })}$ is the mean body weight of fish from the treatment and $\mathrm{BW}_{(\mathrm{s})}$ is the 158 body weight of the individual fish. The \% remaining of digesta contents was calculating by 
159 dividing $\mathrm{X}_{\mathrm{DG}(\mathrm{ss})}$ by the mean $\mathrm{X}_{\mathrm{DG}(\mathrm{ss})}$ generated for fish sampled at the first time point (1.5h) and 160 multiplying by 100 . For microbeads and microfibers, \%remaining was calculated by dividing the 161 number of microplastics measured in a fish's digestive tract by 50 and multiplying by 100. Where time is the time since feeding (h), group represents a categorical variable specified as 165 166

$$
\text { Model }=\text { Time }+ \text { Group }+ \text { Time } * \text { Group }+ \text { Constant }
$$
cases where the interaction term (Time * Group) was non-significant, analysis of covariance (ANCOVA) was performed to adjust for time as a covariate and increase the statistical power of the group comparison test. Where the interaction term was found to be significant, GLMs were performed on subsets of the data to test for differences between selected group comparisons. GLM(1) tested for differences in digesta retention time between treatment 1 and treatment 2. $\operatorname{GLM}(2)$ tested for differences in digesta retention time and microfiber retention from measurements taken in treatment $1 . \operatorname{GLM}(3)$ tested for differences in digesta retention time and microbead retention from measurements taken in treatment 2. Finally, GLM(4) tested for differences in microfiber and microbead retention. Data transformation was necessary owing to failure of normality of the $\%$ retention data on the combined data (digesta, microbeads and microfibers). However, when the fist time point $(1.5 \mathrm{~h})$ was removed, transformation of $\%$ retention data by natural $\log$ transformation yielded a normal data set ( $\mathrm{p}>0.05$; Lillefor's test). Thus, statistical comparisons by GLM were performed with the $1.5 \mathrm{~h}$ time point removed and applying a ln transformation. Non-transformed digesta retention data (inclusive of the $1.5 \mathrm{~h}$ time point) for individual fish were subsequently fit to an exponential model using non-linear least squares regression according to: 
Where 100 is constant forcing $100 \%$ of gut contents retention at time 0 , b is the fitted coefficient and time is time since feeding (h). The ability of Eq. 2 calibrated independently to gut contents to predict microplastic retention was evaluated using goodness of fit tests by performing a linear regression on observed (microplastic) vs model (Eq. 2) predicted digesta retention. The goodness of fit result was evaluated by determining if the slope was significantly different from 1 , the constant was significantly different from 0 and by evaluating the magnitude of the coefficient of determination. All statistics were performed using Systat 13 statistical software. Except where otherwise noted, measures of central tendency and variation are expressed as mean and standard error (SE).

\subsection{Results and Discussion}

\subsection{Digesta retention}

During experimental trials, all fish were observed to consume the microplastic amended treatment pellet. No fish mortalities occurred nor were there apparent signs of distress following exposure to the amended food pellet. Fish sacrificed at the $1.5 \mathrm{~h}$ time point had a mean $\mathrm{X}_{\mathrm{DG}(\mathrm{ss})}$ weight of $0.60 \pm 0.04 \mathrm{~g}$. This corresponds to a food consumption of $2.32 \%$ body weight across the treatments and is consistent with expected food consumption rates in fasted fish.

A general linear model (GLM(1) as described in methods) was performed to compare \% retention of digesta between the two treatments. The GLM and ANCOVA revealed a nonsignificant $\left(\mathrm{F}_{1,39}=0.92 ; \mathrm{p}>0.3 ;\right.$ ANCOVA $)$ difference in digesta retention between the treatments after adjusting for time as a covariate. Given that digesta retention did not significantly differ between the two treatments, the data were combined and fit to the exponential model yielding the following solution: 


$$
\% \text { Retained }=100 \cdot e^{-0.069 \cdot \text { time }} ; \mathrm{R}^{2}=0.69
$$

Based on Eq. 3, the time to evacuate $50 \%$ and $90 \%$ of digesta was 10.0 and $33.4 \mathrm{~h}$, respectively. Overall, the exponential model fit described the temporal trends of digesta contents well during the first $24 \mathrm{~h}$ but tended to underestimate observed digesta contents at longer time points (Figure 2). This may be related to the method of separating gut contents from the intestinal tissues which could have included residual gut secretions and/or sloughed cells/tissues generated from the GItract processing method itself. However, the fitted model produced retention estimates that were generally consistent with other studies on digesta retention in fish of similar size and temperature. Stehlik et al., (2014) reported full clearance of gut contents from clearnose skate (Raja eglanteria) by $48 \mathrm{~h}$ when held at $15^{\circ} \mathrm{C}$. Yellow perch held at $17.1^{\circ} \mathrm{C}$ exhibited a gut evacuation coefficient of $0.035 \cdot$ time $\left(\mathrm{h}^{-1}\right)$ based on a log linear model which implies a $50 \%$ digest retention of $19.8 \mathrm{~h}$ and $90 \%$ retention of $65 \mathrm{~h}$ (Gringas and Boisclair, 2000).

\subsection{Microplastic retention in GI-tracts}

Control fish sacrificed after $1.5 \mathrm{~h}$ were examined for evidence of microplastics in gut contents and carcass samples. No microplastics were found in control fish or within their gut contents. In addition, 10 control fish pellets were examined for presence of microplastics. Similar to control fish, microplastics were not observed in non-ammended food pellets.

During the first sampling point $(1.5 \mathrm{~h})$, there was good recovery of microplastics within the gut contents of treatment fish. For microfibers, 2 fish had 50 microfibers recovered (100\% recovery) and the third fish had 48 fibers recovered in the GI-tract. For the microbeads, 40 to 44 particles (80-84\% recovery) were recovered from fish during the first time point. Small numbers 
227 of microplastics were recovered at the $144 \mathrm{~h}$ time point (1 to 3 microfibers in replicate $144 \mathrm{~h}$ 228 sampled fish and 0 to 3 microbeads in triplicate fish).

A general linear model (GLM) was applied to test percent retention of all treatments (digesta from each treatment, microbeads and microfibers) within the study. Both Time $\left(\mathrm{F}_{1,76}=\right.$ 88.1; $\mathrm{p}<0.001)$ and the Group $\mathrm{x}$ Time $\left(\mathrm{F}_{3,76}=3.09 ; \mathrm{p}<0.05\right)$ interaction terms were significant but 232 group was not significant $\left(\mathrm{F}_{3,76}=0.212 ; \mathrm{p}>0.8\right)$ in the overall GLM. Due to the significant interaction terms, additional GLMs were applied to subsets of the data to evaluate for differences 234 in retention on selected measurements. $\operatorname{GLM}(2)$ and the ANCOVA revealed no significant 235 differences $(\mathrm{F} 1,39=0.959 ; \mathrm{p}>0.5 ; \mathrm{ANCOVA})$ in microfiber and digesta retention. Similarly, $236 \mathrm{GLM}(3)$ and ANCOVA revealed non-significant $(\mathrm{F} 1,39=4.00 ; \mathrm{p}>0.05 ;$ ANCOVA) differences in 237 microbead retention from gut digesta retention. Finally, a comparison of microfiber and 238 microbead retention yielded non-significant differences $(\mathrm{F} 1,39=0.678 ; \mathrm{p}>0.4$; ANCOVA) from 239 one another. Microplastic and microfiber retention with time along with digesta contents trends $240 \quad$ are presented in Figure 2.

For microfibers, the linear regression between $\%$ microfiber retention and gut digesta 242 model (Eq. 3) prediction yielded a slope of $0.96 \pm 0.09$, constant of (7.33 \pm 4.07$)$ and coefficient of 243 determination $\left(\mathrm{R}^{2}\right)$ of 0.85 . The above slope was not significantly different from unity $244\left(\mathrm{t}_{1,22}=0.042 ; \mathrm{p}>0.5 ; \mathrm{t}\right.$-test $)$ and the constant was not different from zero $\left(\mathrm{t}_{1,22}=1.80 ; \mathrm{p}>0.05 ; \mathrm{t}\right.$ 245 test). For microbeads, the goodness of fit test produced a similar slope $(0.94 \pm 0.04)$ that was not 246 significantly different from unity $\left(\mathrm{t}_{1,22}=1.44 ; \mathrm{p}>0.1\right.$; $\mathrm{t}$-test $)$ and constant $(3.67 \pm 2.06)$ not 247 significantly different from zero $\left(\mathrm{t}_{1,22}=1.79 ; \mathrm{p}>0.05\right.$; $\mathrm{t}$-test $)$ with an $\mathrm{R}^{2}$ of 0.95 . It is perhaps 248 notable that the digesta retention model (Eq. 3) which was calibrated only to digesta retention 249 data explained even more variation in microplastic retention than digesta contents itself. This 
250 was mainly related to the better fit of model predictions to microplastic retention at the later time

251 points (Figure 2). The reason for the differences in model fit across measurements is attributed

252 to the fact that microplastic exposure was controlled with a high degree of precision compared to

253 gut contents. Although each fish was given exactly 50 microplastic particles, they were provided

254 with food ad libitum after verifying their consumption of the microplastic amended pellet. Thus,

255 digesta contents would have varied to a greater extent between fish compared to microplastic

256 exposures. Overall the goodness of fit tests indicates that the gut digesta retention model

257 adequately described the retention of both microplastic types.

258 Similar observations were generated for the marine isopod Idotea emerginata fed a diet

259 spiked with microplastic particles and fibers (Hämer et al,. 2014). In the study by Hämer et al.,

260 (2014), microplastic particles appeared in the stomach and gut contents of isopods but were also

261 readily egested with the feces. Mazurais et al. (2015) examined microplastic retention in

262 European sea bass (Dicentrarchus labrax) larvae when exposed to microplastics added to food.

263 The above authors observed a correlation between microbeads in the gut of larvae with

264 concentration of microbeads added to the diet. However, the authors noted that microbeads were

265 fully cleared from the gut of larvae after 2 days post exposure and could be identified in feces

266 suggesting passive retention in the gut contents of fish.

267 Microplastics were also examined in carcass samples of treatment fish but were not

268 observed apart from the gut tissue and gut contents analyzed separately and discussed above.

269 This differs from the results of Avio et al., (2015b) who observed translocation of polyethylene

270 and polystyrene microplastics to liver of laboratory held mullet (Mugil cephalus) exposed to

271 microplastics in water (nominal microplastic dose was $2.5 \times 10^{3}$ particles/L of polyethylene or

272 polystyrene particles sized from 100 to $1000 \mu \mathrm{m}$ ) for 7 days. Between 1-2 microplastic particles 
273 per individual were detected in liver of exposed fish, although the presence of microplastics in

274 liver was two orders of magnitude lower than what was observed in gut contents of fish.

275 Similarly, Lu et al. (2016) exposed zebrafish (Danio rerio) to solutions containing 5 or $20 \mu \mathrm{m}$

276 diameter polystyrene microplastics at concentrations of between $4.5 \times 10^{6}$ to $2.9 \times 10^{8}$ particles/L

277 for 7 days. The above authors reported that $5 \mu \mathrm{m}$ microplastics accumulated in fish gills, liver

278 and gut, whereas larger microplastics (20 $\mu \mathrm{m}$ in diameter) accumulated only in fish gills and gut

279 but not in liver. Time to steady state of microplastics in zebra fish was reported to be $48 \mathrm{~h}$,

280 implying rapid clearance from animals consistent with the gut retention data presented here (Lu

281 et al., 2016). While the present study failed to identify microplastic translocation in fish tissues

282 apart from their detection in the GI tract, this could be a function of exposures to different

283 microplastic types, different dosing strategies, levels of exposures and differences in the method

284 of detection of microplastics in exposed animals. The lack of translocation of larger $(20 \mu \mathrm{m}$

285 plus) sized microbeads to liver in zebra fish as reported by Lu et al., (2016) is consistent with the

286 present work given that particles greater than $63 \mu \mathrm{m}$ were utilized but is not consistent with Avio

287 et al. (2015b) who exposed fish to microplastics of comparable size to this research. Avio et al.,

288 (2015b) and Lu et al., (2016) provided continuous exposures of fish to microplastic contaminated

289 water for up to $7 \mathrm{~d}$ days compared to a single dose from a microplastic amended meal applied in

290 the present study. The above authors also used nominal microplastic concentrations in water that

291 were considerably higher than what is present in natural waters. Avio et al., (2015b) used a more

292 sensitive microplastic extraction/detection technique that employed a combination of density

293 gradient separation and oxidant treatment which was shown to yield higher recoveries of

294 microplastics from animal tissues then the oxidation treatment alone. Lu et al., (2016) utilized

295 microplastic particles with encapsulated fluorescent dies to facilitate their detection in tissues 
296 which potentially yielded much lower detection limits then the visual method employed here.

297 Thus, even though microplastics had very good recovery in pellets and gut contents of early time

298 point sacrificed fish from the present work, translocation of smaller microplastic particles when

299 exposed at higher concentrations or under long term exposures cannot be ruled out based on the 300 results of this study.

\subsection{Conclusions}

Microplastics of two distinct particle shapes (microbeads and microfibers) exhibited 304 similar retention in the GI-tract of goldfish compared to bulk food and digesta. Although a small 305 number of particles were retained in fish after 6 days of fasting, there was no evidence for net 306 bioaccumulation of microplastics in the GI-tract or internal translocation to tissues of fish post 307 exposure. This implies that the potential for long term entrainment and retention of textile 308 derived microfibers or PCP-derived microbeads in fish is relatively low and the detection of 309 microplastics in fish gut contents in the environment most likely represents recent exposures to 310 microplastics in the diet as opposed to cumulative retention across multiple meals. However, this 311 study was limited to evaluation of only two microplastic types and one species of fish. As such,

312 further research to characterize microplastic retention by fish species over different plastic types, 313 shapes and dietary concentrations may be warranted.

\section{$315 \quad 5.0$ Acknowledgment}

316 This study was funded by the University of Windsor's Healthy Great Lakes Research Fund and a

317 Natural Sciences and Engineering Research Council (NSERC) Discovery Grant to K.G. 
318 Drouillard. The authors would also like to thank Mr. Todd Leadley for his help setting up the 319 animal husbandry facilities.

\subsection{References}

322

323

324

325

326

327

328

329

330

331

332

333

334

335

336

337

Andrady A.L. (2011) Microplastics in the marine environment. Mar. Pollut. Bull. 62: 1596-1605. DOI: 10.1016/j.marpolbul.2011.05.030

Avio, C.G., Gobri, S., Milan, M., Benedetti, M., Fattorini, D., D'Errico, G., Pauletto, M., Bargelloni, L., Regoli, F. (2015a) Pollutant bioavailability and toxicologic risk from microplastics to marine mussels. Environ Pollu 198:211-222. DOI: 10.1016/j.envpol.2014.12.021

Avio, C.G., Gorbi, S., Regoli, F. (2015) Experimental development of a new protocol for extraction and characterization of microplastics in fish tissues: first observations in commercial species from Adriatic Sea. Mar Environ Res 111:18-26. DOI: 10.1016/j.marenvres.2015.06.014

Bellas, J., Martinez-Armental, J., Martinez-Cámara, A., Basada, V., Martinez-Gómez, C. (2016) Ingestion of microplastics by demersal fish from the Spanish Atlantic and Mediterranean coasts. Mar Pollut Bull DOI: 10.1016/j.marpolbul.2016.06.026

Besseling, E., Wegner, A., Foekema, E. M., van den Heuvel-Greve, M. J., \& Koelmans, A. A. (2012) Effects of microplastic on fitness and PCB bioaccumulation by the lugworm Arenicola marina (L.). Environ Sci Technol 47: 593-600. DOI: 10.1021/es302763x 
Biginagwa, F.J., Maymoa,B.S., Shashoua, Y., Syberg, K., Khan, F.R. (2016) First evidence of microplastics in the African Great Lakes: Recovery from Lake Victoria Nile perch and Nile tilapia. J Great Lakes Res 42:146-149. DOI 10.1016/j.jglr.2015.10.012

Browne, M.A., Dissanyake, A., Galloway, T.S., Lowe, D.M., Thompson, R.C. (2008) Ingested microscopic plastic translocates to the circulatory system of the mussel, Mytilus edulis (L.). Environ Sci Technol 42:5026-5031. DOI: 10.1021/es800249a

Browne, M.A. (2011) Accumulation of microplastic on shorelines worldwide: sources and sinks. Environ Sci Technol 45:9175-9179. DOI: 10.1021/es201811s

Browne, M.A., Niven, S.J., Galloway, T.S., Rowland, S.J., Thompson, R.C. (2013) Microplastic moves pollutants and additives to worms, reducing functions linked to health and biodiversity. Curr Biol 23:2388-2392. DOI: 10.1016/j.cub.2013.10.012

Collignon, A., Hecq, J.H., Galgani, F., Collard, F., Goffart, A. (2014) Annual variation in neustonic micro-and meso-plastic particles and zooplankton in the Bay of Calvi (Mediterranean-Corsica). Mar Pollut Bull 79: 293-298. DOI: 10.1016/j.marpolbul.2013.11.023

Corcoran, P.L. (2015) Benthic plastic debris in marine and freshwater environments. Environ Sci (Processes and Impacts): 17:1363-1369. DOI: 10.1039/c5em00188a

Eerkes-Medrano, D., Thompson, R.C., Aldridge, D.C. (2015) Microplastics in freshwater systems: A review of the emerging threats, identification of knowledge gaps and prioritisation of research needs. Wat Res 75:63-82. DOI: 10.1016/j.watres.2015.02.012 
Environment Canada (2015). Microbeads - A science summary. Unpublished report. http://www.ec.gc.ca/ese-ees/ADDA4C5F-F397-48D5-AD173F989EBD0E5/Microbeads_Science\%20Summary_EN.pdf (Accessed March 23, 2016).

Eriksen, M., Lebreton, L.C.M., Carson, H.S., Theil, M., Mooree, C.J., Borerro, J.C., Galgani, F, Ryan, P.G., Reisser, J. (2014). Plastic Pollution in the World's Oceans: More than 5 Trillion Plastic Pieces Weighing over 250,000 Tons Afloat at Sea. PLoS One 9: 12. DOI: 10.1371/journal.pone.0111913

Frias, J.P.G.L., Otero, V., Sobral, P. (2014). Evidence of microplastics in samples of zooplankton from Portuguese coastal waters. Mar Environ Res 95: 89-95. DOI: 10.1016/j.marenvres.2014.01.001

Gingras, J., Boisclair, D. (2000). Comparison between consumption rates of yellow perch (Perca flavescens) estimated with a digestive tract model and with a radioisotope approach. Can J Fish Aquat Sci 57: 2547-2557. DOI: 10.1139/cjfas-57-12-2547

Hämer, J., Gutow, L., Köhler, A., Sabrowoski, R. (2014) Fate of microplastics in the marine isopod Idotea emerginata. Environ Sci Technol 48:13541-13458. DOI: $10.1021 /$ es501385y

Lönnstedt, O.M., Eklöv, P. (2016) Environmentally relevant concentrations of microplastic particles influences larval fish ecology. Science 352:1213-1216. DOI: 10.1126/science.aad8828

Lusher A.L., McHugh, M., Thompson, R.C. (2013) Occurrence of microplastics in the gastrointestinal tract of pelagic and demersal fish from the English Channel. Mar Pollut Bull 67: 94-99. DOI: 10.1016/j.marpolbul.2012.11.028 
380

381

382

383

384

385

386

387

388

389

390

391

392

393

394

395

396

397

398

399

Lu, Y., Zhang, Y., Deng, Y., Jiang, W., Zhao, Y., Geng, J., Ding, L., Ren, H. (2016). Uptake and accumulation of polystyrene microplastics in zebrafish (Danio rerio) and toxic effects in liver. Environ Sci Technol 50:4054-4060. DOI 10.1021/acs.est.6b00183

Mazurais, D., Ernande, B., Quazuguel, P., Severe, A., Huelvan, C., Madec, L. Mouchel, O., Soudant, P., Robbens, J., Huvet, A., Zamonino-Infante, J. (2015) Evaluation of the impact of polyethylene microbeads ingestion in European sea bass (Dicentrarchus labrax) larvae. Mar Environ Res 112:78-85. DOI: 10.1016/j.marevres.2015.09.009

Neves, D., Sobral, P. Ferreira, J.L., Pereira, T. (2015) Ingestion of microplastics by commercial fish off the Portuguese coast. Mar Pollut Bull 101:119-126. DOI: 10.1016/j.marpolbul.2015.11.008

Pedà, C., Caccamo, L., Fossi, M.C., Gai, F., Andaloro, F., Genovese, L., Perdichizzi, A., Romeo, T., Maricchiolo, G. (2016) Intestinal alterations in European sea bass Dicentrarchus labrax (Linnaeus, 1758) exposed to microplastics: Preliminary results. Environ Pollut 212:251-256. DOI: 10.1016/j.envpol.2016.01.083

Phillips, M.B., Bonner, T.H. (2015) Occurrence and amount of microplastic ingested by fishes in watersheds of the Gulf of Mexico. Mar Pollut Bull 100:264-269. DOI: 10.1016/j.marpolbul.2015.08.041

Rehse, S., Kloas, W., Zarfl, C. (2016) Short-term exposure with high concentrations of pristine microplastic particles leads to immobilisation of Daphnia magna. Chemosphere 153:9199. DOI: 10.1016/j.chemosphere.2016.02.133 
400

401

402

403

404

405

406

407

408

409

410

411

412

413

414

415

416

417

Sánchez, W., Bender, c., Porcher, J.M. (2014). Wild gudgeons (Gobia gobia) from French rivers are contaminated by microplastics: Preliminary study and first evidence. Environ Res 128:98-100. DOI: 10.1016/j.envres.2013.11.004

Setälä, O., Fleming-Lehtinen, V., Lehtiniemi, M. (2014) Ingestion and transfer of microplastics in the planktonic food web. Environ Pollut 185: 77-83. DOI: 10.1016/j.envpol.2013.10.013

Stehlik, L.L., Phelan, B.A., Rosendale, J., Hare, J.A. (2015). Gastric evacuation rates in male clearnose skate (Leucoraja eglanteria) in the laboratory. J Northwest Atl Fish Sci 47: 2936. DOI: $10.2960 /$ j.v47.m700

Von Moos, N., Burkhardt-Holm, P., Köhler, A. (2012) Uptake and effects of microplastics on cells and tissue of the blue mussel Mytilus edulis L. after an experimental exposure. Environ Sci Technol 46: 11327-11335. DOI: 10.1021/es302332w

Waters, C.N., Zalasiewicz, J., Summerhays, C., Barnosky, A.D., Poirier, C., Galuszka, A., Cearreta, A., Edgeworth, M., Ellis, E.C., Ellis, M., Jeandel, C., Leinfelder, R., McNeill, J.R., Williams, M., Zhisheng, A., Grinevald, J., Odada, E., Oreskes, N., Wolfe, AP. (2016) The Anthropocene is functionally and stratigraphically distinct from the Holocene. Science 351(6269):137-147. DOI: 1126/science.aad2622. 


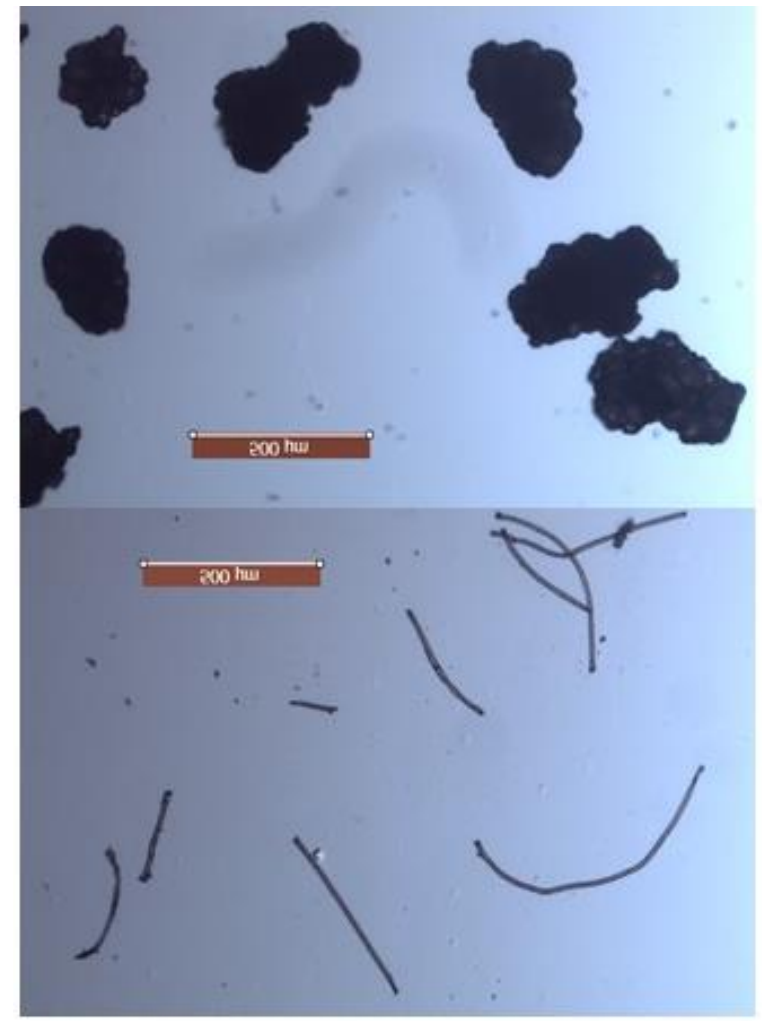

Figure 1. Image of microbeads (left) and microfibers (right) used for feeding trials ( $5 \mathrm{x}$ magnification). 

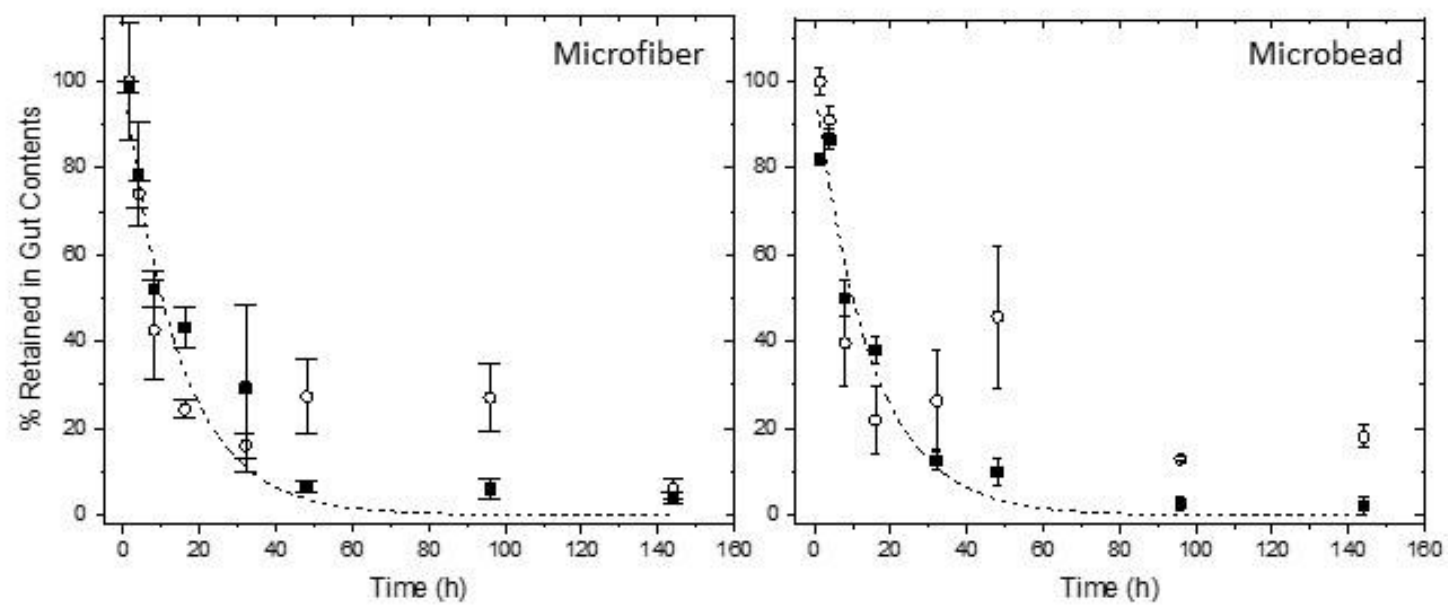

Figure 2. Gut retention of digesta and microplastics in gold fish post feeding. Left graphic presents mean microfiber $(\boldsymbol{\Xi})$ retention compared to digesta $(\mathrm{O})$. Right graphic presents mean microbeads ( $\mathbf{a})$ retention compared to digesta $(\mathrm{O})$. Dashed line is the exponential fit to the combined digesta retention data (Eq. 3). Error bars are standard error. 